\title{
Estratégia de Fusões e Aquisições: Eficácia na Expansão das Plataformas de Produtos em Empresas de Autopeças
}

\author{
Moisés Ari Zilber \\ Eugen Erich Piekny
}

\begin{abstract}
Resumo
O presente estudo analisa a relação entre a estratégia de fusões e aquisições e a expansão das plataformas de produtos nas empresas de autopeças instaladas em São Paulo. O foco deste estudo consistiu em verificar se a estratégia de F\&A foi eficaz na desejada ampliação da plataforma de produtos. Estudo exploratório foi conduzido a partir de fontes primárias com base na coleta dos dados obtidos nas entrevistas em profundidade junto aos executivos principais das empresas pesquisadas. Após a coleta, tratamento, análise e interpretação dos dados, a pesquisa indicou num primeiro momento uma tendência de se comprovar e não refutar a hipótese formulada no início deste trabalho que considera a estratégia de fusões e aquisições eficaz para a ampliação da plataforma de produtos nas empresas de autopeças.
\end{abstract}

Palavras-chave: estratégia; fusão; aquisição; produto.

\begin{abstract}
The present study analyses the relation between the strategy of mergers and acquisitions and the increasing of platform of products in the auto part companies installed in São Paulo. The focus of this study consisted of verifying if F\&A strategy would have been effective in the desired magnifying of the platform of products in the auto part companies. An exploratory study was lead from primary sources through the collection of data obtained in the depth interviews to the main executives of the searched companies. After the collection, treatment, analysis and interpretation of the data the research indicated at a first moment a trend of proving and not refuting the hypothesis formulated in the beginning of this work which considers strategy of merger and acquisitions effective for magnifying platform of products in the auto part companies.
\end{abstract}

Key words: strategy; merger; acquisition; product. 


\section{INTRODUÇÃO}

O propósito deste trabalho foi o de avaliar a eficácia da estratégia de fusões e aquisições (F\&A) para a ampliação da plataforma de produtos nas empresas de autopeças. A expressão plataforma de produtos é utilizada por Deschamps e Nayak (1997) para designar o conjunto de todas as diferentes linhas e itens de produtos que uma empresa possui e coloca à venda no mercado.

A escolha do tema decorre do intenso movimento de F\&A ocorrido na última década na indústria de autopeças instaladas no Brasil e da vinda de novas montadoras ao país, promovendo mudanças na relação entre elas e seus fornecedores de autopeças.

Robles (2001) afirma que as montadoras vêm apresentando importantes transformações na sua forma de atuar, estabelecendo diferentes tipos de relacionamentos com seus fornecedores. Essa mudança é percebida nos novos modelos de organização da produção: as empresas de autopeças passaram a ser responsáveis pelas submontagens, assumindo a função de sistemistas. Além disso, a concorrência entre essas empresas passou a ser realizada em escala mundial, conhecida por global sourcing.

Considerando a reestruturação ocorrida no setor de autopeças, este estudo procurou identificar a relação entre a estratégia de F\&A e as plataformas de produtos nas empresas de autopeças.

\section{Problema de Pesquisa e Objetivo do Estudo}

Algumas empresas de autopeças, com objetivo de crescimento empresarial, perceberam a necessidade de ampliar sua plataforma de produtos em curto espaço de tempo; segundo Zilber et al. (2002) essa mudança deveria possibilitar a oferta de novos produtos com tecnologia avançada. As indústrias de autopeças deveriam oferecer, em curto espaço de tempo, uma plataforma de produtos tão completa quanto à ofertada pelos fornecedores mundiais. Assim, conforme verificado por esses autores, precisavam reagir de forma eficaz e reformular rapidamente sua oferta e a alternativa de se fazer investimentos internos para o desenvolvimento de novos produtos não era interessante, pois demandaria muito tempo, de modo que optaram pela implementação da F\&A para atender a esse objetivo. 
Estudo de Rocha et al. (2000, p. 1), abrangendo diferentes setores industriais brasileiros que implementaram a F\&A, concluiu que "não há evidência de aumento da rentabilidade das empresas até dois anos após sua aquisição". Para os autores a explicação está longe de ser óbvia, havendo necessidade de se aprofundar o conhecimento a respeito da reestruturação da indústria brasileira, decorrente do intenso movimento de F\&A na última década.

Baseando-se nas afirmações acima, algumas favoráveis e outras desfavoráveis à $\mathrm{F} \& \mathrm{~A}$, surgiu a idéia de se conhecer melhor a relação existente entre essa estratégia e a indústria de autopeças, a qual precisou solucionar em curto espaço de tempo a ampliação da plataforma de produtos. Dentro desse raciocínio emergiu a questão: a estratégia de F\&A revela-se eficaz para a ampliação da plataforma de produtos nas empresas de autopeças?

Segundo Marcovitch e Zaccarelli (1972), os parâmetros para se avaliar o sucesso de uma organização são a produtividade, a eficiência e a eficácia. Para Gonçalves (1984), é freqüente a confusão feita entre eficácia e eficiência, pois eficácia significa comparar as realizações atribuíveis a um programa com as realizações pretendidas, e eficiência diz respeito aos objetivos atingidos em relação aos recursos consumidos. O autor defende que "a eficácia de cada estratégia é estimada a partir do efeito que terá nos objetivos do sistema” (GONÇALVES, 1984, p. 68). Considerando que este trabalho procurou avaliar a eficácia da estratégia de F\&A, esta avaliação do efeito da F\&A nos objetivos da organização foi estudada comparando-se as realizações obtidas nas plataformas de produtos com as realizações pretendidas. Assim, se o objetivo é alcançado então essa estratégia é eficaz; caso contrário, não é eficaz.

Dessa maneira, o objetivo deste estudo foi o de avaliar a eficácia da estratégia de F\&A para a ampliação da plataforma de produtos nas empresas de autopeças e partiu-se da hipótese de que a estratégia de F\&A para a ampliação da plataforma de produtos nas empresas de autopeças é eficaz.

\section{Referencial Teórico}

Ansoff e McDonnell (1993) defendem que a estratégia é um conjunto de regras de tomada de decisão para orientação do comportamento de uma organização e representa os meios para se atingir os objetivos que a empresa tenta alcançar. Abordando uma unidade de negócio, Porter (1998) afirma que a estratégia significa fazer escolhas de posicionamento competitivo e sua essência é 
decidir o que não fazer. Na sua visão, a estratégia deve ser arquitetada conjugando valor, posição única e valiosa, escolhas de posicionamento competitivo, integração e adaptação de atividades; somente com a otimização desses parâmetros a estratégia será capaz de trazer competitividade e sustentabilidade, proporcionando uma combinação única de valor para o cliente. A proposição de Wright et al. (2000) alinha-se com Ansoff e McDonnell (1993) sendo mais genérica que a de Porter (1998) ao defenderem que estratégia se refere aos planos da alta administração para alcançar resultados consistentes com a missão e objetivos gerais da organização.

Em decorrência da posição desses autores, pode-se afirmar sucintamente que a estratégia é a busca deliberada de um plano de ação por parte da alta administração para alcançar resultados consistentes com os objetivos gerais da organização.

Mintzberg e Lampel (1999) identificaram dez escolas possíveis para a formação das estratégias e afirmam que momentos diferentes induzirão a formação de estratégias oriundas de escolas diferentes, revelando a importância do cenário vivido pela empresa no momento da escolha da estratégia. A escola de configuração, defendida pelos autores, considera a formação de estratégia como processo que abrange todas as escolas existentes, cada uma delas representando uma parte do processo. Essa escola oferece uma visão holística, onde Porter contribuiria na etapa de formação da estratégia por meio da escola de posicionamento.

Outro enfoque é oferecido por Barney (1995), ao definir os recursos da empresa como origem básica da rentabilidade, com uma visão próxima de Prahalad e Hamel (1998) ao diferenciarem recursos e competências essenciais. Os autores são enfáticos ao afirmarem que no longo prazo a vantagem competitiva reside nas competências.

Considerando a estratégia ser função das forças ambientais e das competências disponíveis na empresa, pode-se defender um processo de formação de estratégia que contemple no primeiro passo a teoria da escola de posicionamento, e no segundo, os recursos e as competências necessárias para a implementação das estratégias definidas no passo anterior.

Dentro desse conceito teórico, o crescimento da empresa é uma estratégia possível. Assim, Wright et al. (2000) defendem que a fusão é uma estratégia de crescimento na qual duas ou mais empresas combinam-se para formar uma nova empresa. Reed e Lajoux (1995) e Wright et al.(2000) alinham-se, ao afirmarem que uma fusão ocorre, quando uma empresa é combinada com outra 
e desaparece dentro dessa outra. A nova empresa surgida após a fusão é referida como empresa sucessora (REED; LAJOUX, 1995).

Wright et al. (2000) salientam que a fusão pode ser classificada em horizontal ou vertical:

. Fusão horizontal - ocorre entre empresas que produzem o mesmo tipo de bem/ serviço.

. Fusão vertical - ocorre entre uma empresa e uma de suas fornecedoras ou clientes.

De acordo com Key (1992), legalmente a fusão é definida como a operação pela qual se unem duas ou mais sociedades a fim de formar uma nova sociedade; esta última lhes sucederá nos direitos e obrigações, extinguindo as sociedades envolvidas e dando lugar a uma nova.

Conclui-se que a fusão pode ser entendida como estratégia de nível empresarial em que uma empresa se combina com outra e ambas se consolidam dando origem a uma sucessora, disposta estrutural e organizacionalmente para se desenvolver e crescer.

Reed e Lajoux (1995) defendem que a aquisição é uma estratégia empresarial de crescimento, na qual as ações ou ativos de uma empresa passam a pertencer a um comprador, e aquisição é o termo genérico usado para descrever a mudança de proprietário. O que diferencia a aquisição da fusão é o fato desta última poder ou não acontecer após a aquisição. Quanto à finalidade da F\&A, Clemente e Greenspan (1998), Steiner (1969), Wright et al. (2000), Rock et al. (1994), Groppelli e Nikbakht (1999), e Rasmussen (1989), consideram-na como um instrumento para o crescimento da empresa. Finalmente, Rasmussen (1989) defende que tanto a fusão quanto a aquisição são poderosas ferramentas para o crescimento empresarial, possibilitando a penetração em novos mercados em curto prazo, evitando a espera pela maturidade de investimentos internos, a partir da estaca zero. Porter (1986) confirma que a aquisição elimina a necessidade de se promover desenvolvimento interno para a entrada em novos negócios.

Os elementos motivadores para a F\&A defendidos por Rasmussen (1989) e Clemente e Greenspan (1998) são os seguintes:

. Promover o aumento do market share

. Entrar em novos mercados ou ter acesso a novos canais de distribuição

. Obter novos produtos 
- Exercer inovações e descobertas em produtos ou tecnologia para reduzir prazo e custo do produto e melhorar a qualidade

- Reduzir o número de competidores

. Capitalizar em razão de mudanças na política e nas regras

. Fortalecer a reputação e a imagem ou aumentar a credibilidade

. Manter a paz na empresa com ambiente externo de mudanças

Para Steiner (1969), F\&A pode evitar a dependência da empresa em relação às linhas de produtos existentes, sendo sua obsolescência um estímulo para a F\&A, especialmente se a empresa não dispõe de tempo para a modernização a partir de seu próprio esforço de desenvolvimento interno. Clemente e Greenspan (1998) alinham-se a Steiner (1969), ao salientarem que, para evitar a demora no desenvolvimento interno do produto, as empresas que possuem recursos financeiros estão na posição de adquirir outras empresas para ampliar rapidamente sua plataforma de produtos.

As várias colocações dos autores enfatizam a F\&A como estratégia cuja finalidade é o crescimento da empresa a partir de diferentes elementos motivadores.

O processo de formação de estratégias pode dar origem a inúmeras alternativas, fazendo surgir o questionamento das condições sob as quais uma empresa optaria pela F\&A. Ao focarem as competências essenciais das empresas, Prahalad e Hamel (1998, p. 311) questionam: "como pode uma empresa fazer parcerias inteligentemente, sem um claro entendimento das competências essenciais que ela está tentando formar e aquelas que ela está tentando impedir que sejam não intencionalmente transferidas?” Por outro lado, Wright et al. (2000), defendem a vinculação da estratégia aos macroobjetivos empresariais.

Na busca de instrumentos para a análise e escolha da melhor estratégia, alguns são referidos por Wright et al. (2000): Matriz BCG original, Matriz BCG com estrutura revisada, Matriz GE-McKinsey, e Matriz S.W.O.T., sendo que esta última parte do estado do ambiente externo e da posição competitiva de cada unidade de negócio, gerando nove compartimentos de status, e proporcionando uma visão mais detalhada das alternativas, conforme o Quadro 1: 
Quadro 1: Matriz S.W.O.T.

\begin{tabular}{|c|c|c|c|c|}
\hline & \multicolumn{3}{|c|}{ Posição competitiva das unidades de negócio } \\
\hline & & Forte & Média & Fraca \\
\hline \multirow{17}{*}{ 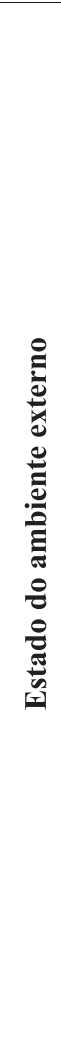 } & \multirow{6}{*}{$\begin{array}{c}\text { Muitas } \\
\text { oportunidades } \\
\text { ambientais }\end{array}$} & Compartimento A & Compartimento D & Compartimento G \\
\hline & & Crescimento interno & Fแก̃̃ & Reviravolta \\
\hline & & Integração vertical & Fusao & (turnaround) \\
\hline & & $\begin{array}{l}\text { de empresas } \\
\text { relacionadas }\end{array}$ & $\begin{array}{l}\text { Integração } \\
\text { horizontal }\end{array}$ & \multirow{3}{*}{ Desinvestimento } \\
\hline & & Fusão & \multirow[b]{2}{*}{ Aliança estratégica } & \\
\hline & & $\begin{array}{l}\text { Integração } \\
\text { horizontal }\end{array}$ & & \\
\hline & \multirow{6}{*}{$\begin{array}{l}\text { Oportunidades e } \\
\text { ameaças } \\
\text { ambientais } \\
\text { moderadas }\end{array}$} & Compartimento B & Compartimento E & Compartimento $\mathrm{H}$ \\
\hline & & Integração vertical & Estabilidade & \multirow{2}{*}{$\begin{array}{l}\text { Reviravolta } \\
\text { (turnaround) }\end{array}$} \\
\hline & & $\begin{array}{l}\text { de empresas } \\
\text { relacionadas }\end{array}$ & Fusão & \\
\hline & & \multirow{3}{*}{$\begin{array}{c}\text { Diversificação } \\
\text { horizontal } \\
\text { relacionada }\end{array}$} & $\begin{array}{l}\text { Integração } \\
\text { horizontal }\end{array}$ & \multirow{3}{*}{ Desinvestimento } \\
\hline & & & Aliança estratégica & \\
\hline & & & Desinvestimento & \\
\hline & \multirow{5}{*}{$\begin{array}{l}\text { Ameaças } \\
\text { ambientais } \\
\text { críticas }\end{array}$} & Compartimento $\mathrm{C}$ & Compartimento F & Compartimento I \\
\hline & & $\begin{array}{c}\text { Diversificação } \\
\text { horizontal } \\
\text { relacionada }\end{array}$ & Desinvestimento & \multirow{4}{*}{ Liquidação } \\
\hline & & $\begin{array}{l}\text { Diversificação } \\
\text { horizontal não } \\
\text { relacionada } \\
\text { (conglomerados) }\end{array}$ & $\begin{array}{l}\text { Diversificação } \\
\text { horizontal } \\
\text { relacionada }\end{array}$ & \\
\hline & & $\begin{array}{l}\text { Integração vertical } \\
\text { de empresas não } \\
\text { relacionadas }\end{array}$ & $\begin{array}{l}\text { Diversificação } \\
\text { horizontal não } \\
\text { relacionada }\end{array}$ & \\
\hline & & Desinvestimento & Estabilidade & \\
\hline
\end{tabular}

Fonte: Wright et al. (2000, p. 159).

Nesta matriz, cada compartimento representa um cenário para o qual se recomenda adotar determinada estratégia. Considerando sua abrangência e profundidade, foi adotada a matriz S.W.O.T. para efeito de se avaliar as funções competitivas e as relações com o ambiente externo.

\section{Plataformas de Produtos}

Steiner (1969) defende que o produto pode ser explicado como algo físico ou mercadoria, sendo um conjunto de satisfações ou benefícios. Ballou (1993) referese aos bens físicos e os categoriza em dois grupos: bens de consumo e bens 
industriais. Stoner e Freeman (1994, p. 46) defendem que "produtos são insumos transformados, que voltam ao ambiente externo sob a forma de bens ou serviços". Para Kotler (1998, p. 310) "um produto é algo que pode ser oferecido a um mercado para satisfazer a um desejo ou necessidade", podendo o produto ser algo na forma de um bem físico, serviço ou idéia. Deschamps e Nayak (1997) defendem que o produto pode ter uma interpretação baseada num conceito mais amplo, que é o de oferta de produtos, englobando:

. O produto primário, item essencial, incluindo seus vários acessórios opcionais.

- O produto secundário, representado pelo serviço técnico que acompanha o produto.

. O produto terciário na forma de suporte de serviço vitalício.

Segundo Christopher (1999, p. 70-71), “os clientes não compram produtos, mas benefícios”.

Deschamps e Nayak (1997) utilizam o termo plataforma de produtos para designar a estrutura da oferta de produtos de que uma empresa dispõe. Kotler (1998) utiliza o termo composto de produto como o conjunto de todas as linhas e itens que uma empresa possui e coloca à venda. Para conhecer o composto de produto ou a plataforma de produtos, deve-se desdobrá-la em suas quatro dimensões:

- A abrangência das linhas, que refere a quantidade de diferentes linhas de produtos.

. A profundidade da linha que refere o número de itens de uma linha de produto.

- A extensão das linhas obtida pela soma do número de itens existentes nas linhas.

. A consistência do composto que indica o grau de relacionamento das linhas entre si.

Exemplo do conteúdo da plataforma de produtos de uma empresa fictícia de autopeças: 


\section{Quadro 2: Composição de uma Plataforma Fictícia de Produtos em Autopeças}

\begin{tabular}{|c|c|c|c|}
\hline & \multicolumn{3}{|c|}{ Abrangência das linhas de produtos } \\
\hline & LINHA 1: motor elétrico & LINHA 2: vela de ignição & LINHA 3: palheta \\
\hline \multirow{6}{*}{ 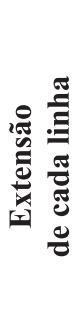 } & Limpador pára-brisa diant. & \multirow{3}{*}{ Motor a gasolina } & \multirow{3}{*}{ Pára-brisa dianteiro } \\
\hline & Limpador pára-brisa tras. & & \\
\hline & Levantador antena elétrica & & \\
\hline & Ventilação interna & \multirow{3}{*}{ Motor a álcool } & \multirow{3}{*}{ Pára-brisa traseiro } \\
\hline & Refrigeração radiador & & \\
\hline & Partida do motor & & \\
\hline
\end{tabular}

Fonte: própria elaborada com base nos dados de Kotler (1998, p. 387).

No quadro acima, a abrangência é composta por três linhas de produtos e a extensão perfaz um total de 10 itens. Na profundidade da linha de motores elétricos, há seis tipos de motores; porém, se para cada tipo houver duas versões, sendo uma disponível para veículos de passeio e outra para veículos de carga, então a profundidade é calculada multiplicando-se 6 × $2=12$, indicando serem oferecidos 12 itens nessa linha de produto.

Quanto à composição da plataforma de produtos, para Ballou (1993) é composta de produtos em diferentes pontos do seu ciclo de vida. Gorle e Long (1976) defendem que a composição ideal deveria conter um mix de produtos em diferentes estágios do ciclo de vida, de modo que, ao iniciar o declínio de um produto maduro, um novo deveria estar no ápice de sua trajetória, assumindo o lugar do anterior na rentabilidade. A reformulação de uma plataforma, segundo Kotler (1998), significa conhecer o lucro e o mercado de cada linha existente e tomar decisões sobre a extensão, modernização e expurgo da linha.

Em função do exposto surge a preocupação da melhor forma de se planejar uma plataforma de produtos capaz de proporcionar desempenho lucrativo para a empresa. Uma ferramenta auxiliar está na análise da demanda, conforme Quadro 3: 


\section{Quadro 3: A Demanda em Função do Produto e do Mercado}

\begin{tabular}{|c|c|c|c|c|}
\hline & \multicolumn{3}{|c|}{ Produto } \\
\hline & & Existente & Modificado & Novo \\
\hline \multirow{3}{*}{ 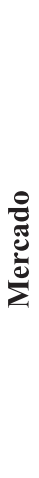 } & $\begin{array}{l}\text { Clientes } \\
\text { atuais }\end{array}$ & $\begin{array}{c}\text { Penetrar mercados, } \\
\text { vendendo mais dos } \\
\text { produtos atuais, a clientes } \\
\text { do tipo dos atuais }\end{array}$ & $\begin{array}{c}\text { Modificar produtos } \\
\text { atuais e vender mais aos } \\
\text { clientes atuais }\end{array}$ & $\begin{array}{c}\text { Desenvolver novos } \\
\text { produtos e vender aos } \\
\text { clientes atuais }\end{array}$ \\
\hline & $\begin{array}{c}\text { Novos } \\
\text { mercados } \\
\text { geográficos }\end{array}$ & $\begin{array}{l}\text { Penetrar outras áreas } \\
\text { geográficas, vendendo ali } \\
\text { os produtos atuais }\end{array}$ & $\begin{array}{l}\text { Modificar produtos } \\
\text { atuais e vender a novos } \\
\text { mercados geográficos }\end{array}$ & $\begin{array}{l}\text { Desenvolver novos } \\
\text { produtos para clientes } \\
\text { potenciais em novas } \\
\text { áreas geográficas }\end{array}$ \\
\hline & $\begin{array}{l}\text { Novos tipos } \\
\text { de clientes }\end{array}$ & $\begin{array}{c}\text { Invadir segmentos, } \\
\text { vendendo os produtos } \\
\text { atuais a novos tipos de } \\
\text { clientes }\end{array}$ & $\begin{array}{l}\text { Modificar produtos } \\
\text { atuais e vender a novos } \\
\text { tipos de clientes }\end{array}$ & $\begin{array}{l}\text { Desenvolver novos } \\
\text { produtos e vender a } \\
\text { novos tipos de clientes }\end{array}$ \\
\hline
\end{tabular}

Fonte: Kotler (1999, p. 67).

Gorle e Long (1976) sugerem que o primeiro critério para selecionar um novo produto deve ser a sua compatibilidade com os pontos fortes da companhia. Quanto ao grau de novidade do produto, o mercado e a empresa são atingidos conforme se observa no Quadro 4:

\section{Quadro 4: Classificação do Novo Produto pela Empresa e pelo Mercado}

\begin{tabular}{|c|c|c|c|}
\hline \multirow{2}{*}{} & $\begin{array}{c}\text { NOVA LINHA DE } \\
\text { PRODUTO }\end{array}$ & $\begin{array}{c}\text { NOVA LINHA DE } \\
\text { PRODUTO } \\
\text { (penetra em um mercado } \\
\text { existente pela primeira vez) }\end{array}$ & $\begin{array}{c}\text { PRODUTO NOVO PARA O } \\
\text { MUNDO }\end{array}$ \\
$\begin{array}{c}\text { (cria um mercado totalmente } \\
\text { novo) }\end{array}$ \\
\cline { 2 - 4 }
\end{tabular}

Fonte: Kotler (1998, p. 275). 
Para Wheelwright e Clark (1992), a capacidade de desenvolvimento de novos produtos em qualquer companhia manufatureira é fundamental para melhorar a posição no mercado e a performance financeira criando novos padrões na indústria e novos nichos de mercado.

Nesta etapa do trabalho, à luz do conhecimento trazido sobre estratégia, fusão, aquisição, eficácia, produto e plataforma de produtos, tornou-se possível conceituar a eficácia da estratégia de F\&A.

\section{Eficácia da Estratégia de F\&A}

Com base no objetivo principal deste trabalho, houve necessidade de se avaliar as mudanças ocorridas nas plataformas de produtos. Utilizando-se dos conceitos discutidos pode-se considerar que se um pretendido objetivo empresarial referente à plataforma de produtos foi alcançado, a estratégia de F\&A adotada pela empresa pode ser considerada eficaz.

Para se conhecer as plataformas de produtos antes e após a F\&A foi necessário caracterizar esses dois momentos. De acordo com Key (1992), a F\&A é dividida em três fases: pré-aquisição, diligência e negociações e pós-aquisição. O início da pré-aquisição ocorre quando um grupo da equipe gerencial é solicitado a avaliar a própria organização em relação às forças e fraquezas. Na diligência e negociações, focalizam-se as finanças; na fase pós-aquisição trabalha-se na implementação dos planos de integração física, financeira, recursos humanos e culturais que encerrados indicam o final da fase pós-aquisição.

Para saber se o objetivo empresarial foi alcançado o critério adotado foi o de se comparar a plataforma pré e pós F\&A e avaliar se houve ampliação ou não.

No Quadro 4, observam-se nove células para a classificação do grau de novidade do produto. Considerando-se as peculiaridades da indústria de autopeças, foram acrescidas em cada célula as letras de A a I, para facilitar a identificação da célula, conforme o Quadro 5: 


\section{Quadro 5: Classificação do Novo Produto pela Empresa e pelo Mercado}

\begin{tabular}{|c|c|c|c|}
\hline $\begin{array}{l}\stackrel{0}{\circ} \\
\frac{\pi}{\sigma}\end{array}$ & $\begin{array}{l}\qquad \boldsymbol{C E} \boldsymbol{E} \boldsymbol{U} \boldsymbol{L} \boldsymbol{A} \boldsymbol{A} \\
\text { NOVA LINHA DE } \\
\text { PRODUTO }\end{array}$ & $\begin{array}{c}\text { CÉL } \boldsymbol{L} \boldsymbol{U} \boldsymbol{L} \boldsymbol{A} \boldsymbol{B} \\
\text { NOVA LINHA DE } \\
\text { PRODUTO }\end{array}$ & $\begin{array}{c}\text { CÉLULA C } \\
\text { PRODUTO NOVO PARA O } \\
\text { MUNDO }\end{array}$ \\
\hline 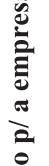 & $\begin{array}{c}\text { CÉ } \boldsymbol{L} \boldsymbol{U} \boldsymbol{L} \boldsymbol{A} \boldsymbol{D} \\
\text { MELHORIA/ REVISÃO DE } \\
\text { PRODUTO EXISTENTE }\end{array}$ & $\begin{array}{c}\text { CÉ } \boldsymbol{L} \boldsymbol{U} \boldsymbol{L} \boldsymbol{A} \boldsymbol{E} \\
\text { MELHORIA/ REVISÃO DE } \\
\text { PRODUTO EXISTENTE }\end{array}$ & $\begin{array}{c}\text { CÉLULA } \boldsymbol{F} \\
\text { ACRÉSCIMO À LINHA DE } \\
\text { PRODUTO EXISTENTE }\end{array}$ \\
\hline 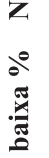 & REDUÇÃO DE CUSTO & $\begin{array}{c}\text { CÉLULA H } \\
\text { MELHORIA/ REVISÃO DE } \\
\text { PRODUTO EXISTENTE }\end{array}$ & REPOSICIONAMENTO \\
\hline
\end{tabular}

Fonte: elaborada com base em Kotler (1998, p. 275).

\section{Metodologia da Pesquisa}

Segundo Gil (1987), o estudo exploratório tem o objetivo de proporcionar visão geral e aproximada acerca de determinado fato. Considerando haver pouco conhecimento sobre a questão da eficácia da F\&A em relação à plataforma de produtos, concluiu-se que este trabalho atende aos pressupostos de um estudo de caráter exploratório.

Com base no intuito de analisar com maior profundidade as opiniões dos executivos quanto à eficácia da F\&A sem contudo quantificar essas opiniões, optou-se por uma pesquisa de campo de caráter qualitativo para obtenção dos dados e da aplicação da técnica de análise de conteúdo para avaliação deles (BARDIN, 1979).

\section{População e Amostra}

No Brasil há um total de 479 empresas de autopeças associadas ao Sindipeças. Esta pesquisa limitou-se às instaladas até $100 \mathrm{~km}$ da cidade de São Paulo cuja população atinge 340 empresas (SINDIPEÇAS, 2002). Considerou-se uma 
amostra por conveniência e as empresas foram selecionadas, levando-se em conta os seguintes requisitos:

. Localizadas até 100 km da cidade de São Paulo.

. Faturamento anual da empresa acima de US\$ 50 milhões.

. Empresa com objetivo de promover o seu crescimento.

. Empresas que optaram pela F\&A com a expectativa de poder ampliar a plataforma de produtos, visando ao crescimento.

- Término da implementação da F\&A ocorrido dentro do período compreendido pela última década.

Em função das restrições de custo, investigou-se uma parte da população, e foi definida uma amostra não probabilista que, segundo Marconi e Lakatos (1990), não pode ser objeto de tratamento estatístico. Para Kerlinger (1980), uma das principais virtudes dos levantamentos é sua surpreendente capacidade de fornecer informação exata sobre populações inteiras, utilizando amostras relativamente pequenas. Com base no exposto, foram eleitas três empresas para compor a amostra, pertencentes ao seleto grupo dos maiores fornecedores mundiais de autopeças.

Vale ressaltar que a partir de informações obtidas junto ao SINDIPEÇAS, os maiores fornecedores mundiais de autopeças compreendem 16 players, atuando de forma global. Em função do sigilo solicitado, os nomes das empresas foram substituídos por empresa 1,2 e 3 . A empresa 1 representa um grupo multinacional classificado em décimo lugar dentre os 16 players mundiais, a empresa 2 ocupa o segundo lugar e a empresa 3 ocupa o quarto lugar.

\section{Coleta de Dados}

A coleta dos dados qualitativos da pesquisa foi efetuada por meio de entrevistas em profundidade, estruturadas segundo roteiro padronizado de modo a facilitar e direcionar o trabalho de levantamento e categorização dos dados. Os entrevistados solicitaram sigilo, e seus nomes foram substituídos por executivo 1 , 2 e 3, cada um correspondendo à respectiva empresa. Os executivos 1 e 3 atuam como presidentes e o executivo 2 acumula a função de diretor de vendas e engenharia do produto. As entrevistas foram gravadas, e o roteiro baseou-se no formulário estruturado em dois blocos de questões, um deles abordando a 
plataforma de produtos antes da F\&A, e o outro após a F\&A, de modo a se conhecer as linhas de produtos em cada um desses momentos. Esta coleta de dados primários foi apoiada por dados secundários, obtidos na forma de catálogos institucionais dos produtos disponíveis em cada empresa pesquisada, servindo de base para as entrevistas e facilitando a abordagem das mudanças ocorridas nas linhas existentes.

\section{Tratamento dos Dados e Resultados}

Conforme Vergara (1998), tratar os dados de forma qualitativa implica codificálos, apresentando-os de forma mais estruturada para a análise. Para Bardin (1979) as categorias são classes que reúnem um grupo de elementos sob um título genérico, devido às características comuns desses elementos. Neste trabalho, o critério adotado para categorização e codificação dos dados está demonstrado no Quadro 6:

\section{Quadro 6: Codificação e Categorização dos Dados}

\begin{tabular}{|c|l|}
\hline Código & \multicolumn{1}{|c|}{ Categoria } \\
\hline & CONTEÚDO DA PLATAFORMA DE PRODUTOS \\
\hline ABR & Abrangência: incluir novas linhas de produtos \\
\hline EXT & Extensão: aumentar determinadas linhas de produtos existentes \\
\hline PRF & Profundidade: adicionar itens em determinado produto de uma dada linha existente \\
\hline & TIPO DE NOVO PRODUTO \\
\hline A & Nova linha de produto, com baixa novidade para mercado e alta para empresa \\
\hline B & Nova linha de produto, média novidade para mercado e alta para empresa \\
\hline C & Produto novo para o mundo, alta novidade para mercado e para empresa \\
\hline D & Melhoria de produto existente, baixa novidade para mercado e média para empresa \\
\hline E & Melhoria de produto existente, média novidade para mercado e empresa \\
\hline F & $\begin{array}{l}\text { Acréscimo à linha de produto existente, alta novidade para mercado e média para } \\
\text { empresa }\end{array}$ \\
\hline G & Produto que sofreu redução de custo, baixa novidade para mercado e empresa \\
\hline H & Melhoria de produto existente, média novidade para mercado, baixa para empresa \\
\hline I & Reposicionamento produto existente, alta novidade para mercado, baixa para empresa \\
\hline
\end{tabular}

Fonte: elaborada com base em Kotler (1998). 
Para tabular os dados foi construída a Tabela 1, que objetiva demonstrar a situação das plataformas de produtos antes e depois da F\&A, de modo a comparar esses dois momentos e cujos dados estão registrados em duas colunas distintas: Expectativas antes da F\&A (início da fase pré-aquisição) e Resultados após a F\&A (final da fase pós-aquisição).

A partir desses dados, a situação das plataformas de produtos foi tabulada em dois grupos: quanto ao conteúdo da plataforma de produtos (códigos ABR, EXT, PRF) e quanto ao tipo de novo produto. A categorização do tipo de novo produto baseou-se nos Quadros.

Os dados coletados junto às empresas pesquisadas foram tabulados; a empresa 1 pode ser utilizada como exemplo para se esclarecer a interpretação da Tabela 1:

\section{Tabela 1: Conteúdo da Plataforma de Produtos e Tipo de Novo Produto, Antes e Depois da F\&A}

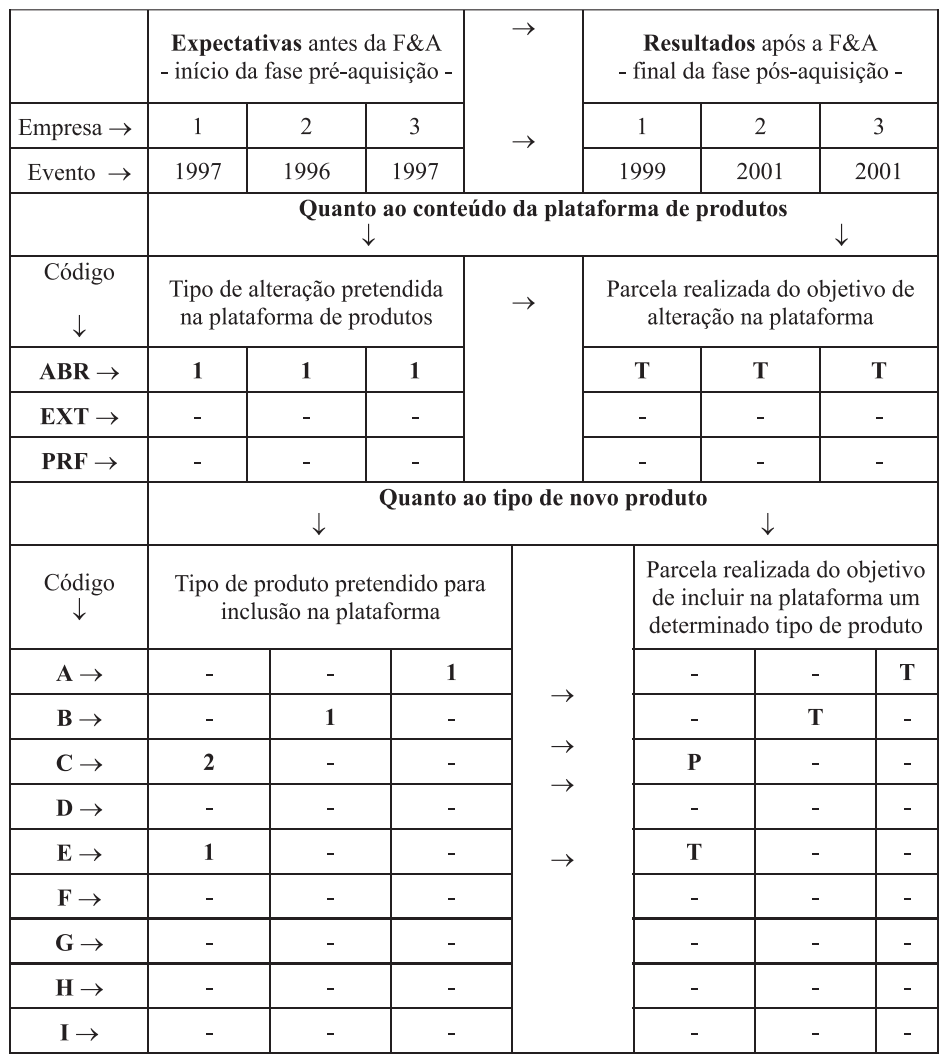

Fonte: entrevistas.

$\mathbf{1}$ = expectativa com prioridade 1 , e $\mathbf{2}$ = expectativa com prioridade 2

$\mathbf{T}=$ objetivo realizado totalmente, e $\mathbf{P}=$ objetivo realizado parcialmente 
- Na coluna Expectativas antes da F\&A indicou-se a Empresa 1 e na linha Evento registrou-se o ano 1997 que marcou o início da fase pré-aquisição.

- Na coluna Resultados após a F\&A a Empresa 1 foi registrada novamente e na linha Evento indicou-se o ano 1999, demonstrando o final da fase pósaquisição.

- Nos dados que abordam o Conteúdo da plataforma de produtos, a resposta indicou a expectativa da Empresa 1 em aumentar a abrangência da linha de produtos, pois considerava esse objetivo como de alta prioridade. Assim, no código ABR e sob a coluna da Empresa 1, Evento 1997 foi indicada a prioridade 1.

- Ainda no grupo de dados que aborda o Conteúdo da plataforma de produtos, a resposta referente à parcela realizada do objetivo de alteração da plataforma indicou que este fora atingido totalmente na opinião do entrevistado. Portanto, na coluna correspondente à Empresa 1, no ano 1999 do Evento e na linha do código ABR foi registrada a letra T.

Por meio das respostas acima, foi possível representar, de forma categorizada e codificada, a mudança ocorrida no conteúdo da plataforma de produtos da Empresa 1. Entendeu-se que a ampliação da abrangência da plataforma de produtos foi realizada totalmente.

A próxima etapa consistiu em saber se o novo produto que promoveu o aumento da abrangência era do tipo desejado, realizando ou não as expectativas havidas antes da F\&A.

- Verificou-se que a Empresa 1 tinha como prioridade 1 a expectativa de incluir um produto do tipo E e como prioridade 2 incluir um produto do tipo C. Portanto, na coluna correspondente à Empresa 1, no ano 1997 do Evento e na direção do código $\mathrm{E}$ foi registrada a prioridade 1 e na direção do código $\mathrm{C}$ foi registrada a prioridade 2 . O código E corresponde a uma melhoria de produto existente com média novidade para o mercado e empresa e o código $C$ representa um produto novo para o mundo com a criação de um mercado totalmente novo. Assim, a prioridade 1 era melhorar um produto existente para posteriormente na prioridade 2 introduzir um produto totalmente novo.

- Os dados indicaram que o objetivo foi atingido totalmente para o produto tipo E, porém no caso do produto $\mathrm{C}$, o objetivo foi atingido parcialmente. Em decorrência, na coluna correspondente à Empresa 1, no ano 1999 do Evento e na direção do código $\mathrm{E}$ foi registrada a letra $\mathrm{T}$ e na direção do código $\mathrm{C}$ houve o registro da letra $\mathrm{P}$. 
E assim sucessivamente foram preenchidos os dados referentes às Empresas 2 e 3, utilizando-se o critério acima detalhado para a Empresa 1. Após a tabulação foi necessário estabelecer um critério que possibilitasse a análise desses dados, discutidos em seguida.

\section{AnÁLISE}

A análise dos dados foi efetuada obedecendo à seqüência adotada no formulário de entrevista; a interpretação dos dados baseou-se na tabulação construída na Tabela 1. Kerlinger (1980, p. 353) caracteriza a análise como sendo a “categorização, ordenação, manipulação e sumarização dos dados. Seu objetivo é reduzir a grande quantidade de dados brutos, passando-os para uma forma interpretável e manuseável, de maneira que características de situações, acontecimentos e de pessoas possam ser descritas sucintamente e as relações entre as variáveis estudadas e interpretadas”.

A análise foi iniciada pelo estudo da variável dependente plataforma de produtos. O resultado mostrou que, no início da fase de pré-aquisição, preponderou entre as empresas a necessidade de fornecerem sistemas completos, de forma a tornarem-se fornecedoras globais de autopeças e à decisão de alterar as plataformas de seus produtos. Não havia produtos considerados em final de ciclo de vida nas suas respectivas plataformas.

Constatou-se que a alteração pretendida foi orientada a partir das oportunidades de demanda na América do Sul e Europa, levando as empresas pesquisadas a planejarem a inclusão de novas linhas de produtos para com isso poderem aumentar a abrangência de suas respectivas plataformas. Em nenhum caso pretenderam aumentar a extensão ou a profundidade de uma determinada linha de produtos existentes.

Quanto ao grau de novidade a ser oferecido ao mercado pelos novos produtos, revelou-se uma tendência intermediária, denotando que os produtos pretendidos não estariam nos extremos do baixo ou do alto grau de novidade.

Das alternativas estratégicas disponíveis, duas empresas optaram pela F\&A, enquanto a terceira optou de início por uma joint venture; mas, depois, mudou essa decisão e implantou uma $F \& A$. As empresas pesquisadas julgaram que com a F\&A a entrada do novo produto no mercado poderia ser rápida e sem a necessidade de aguardar os resultados de investimentos internos em P\&D. 
A análise do cenário no final da fase pós-aquisição evidenciou os resultados obtidos após a implantação das F\&A. A Empresa 1 tinha a expectativa de fornecer uma nova linha de sistema de segurança que não fazia parte de sua plataforma e assim completar a abrangência de produtos disponíveis às montadoras, expectativa que foi totalmente realizada.

A Empresa 2 também realizou totalmente sua expectativa ao complementar sua linha de modulação de freios por meio da F\&A.

A Empresa 3, que havia planejado uma joint venture com a empresa alvo, viu frustrada essa iniciativa durante as negociações e no acordo final optou pela F\&A. Conforme o executivo 3, a expectativa de incluir a nova linha de tapetes moldados foi realizada por meio da F\&A; mas, em razão de a empresa não ter conseguido dispor no mercado da América do Sul o interior completo dos autoveículos, pela falta de competitividade no preço dessa linha de produtos, conforme o conceito de Deschamps e Nayak (1997), o objetivo não foi realizado.

Essa análise indicou que a necessidade de entrada rápida no mercado, com as novas linhas de sistema de segurança e de sistema de freios foi realizada pelas Empresas 1 e 2, o mesmo não ocorrendo com a linha de tapetes moldados da Empresa 3, considerada um fracasso comercial.

Em termos de resultado final para as empresas adquirentes, a Empresa 1 experimentou um crescimento nas vendas impulsionadas pela própria participação da nova linha de sistema de segurança, enquanto a Empresa 2 conseguiu estruturar-se para colocar no mercado de exportação o sistema de freios completo, não conseguindo, no entanto, crescimento das vendas. A Empresa 3 não conseguiu tornar-se fornecedora global de interiores completos de autoveículos, deixando de promover seu crescimento.

Baseando-se no exposto, pode-se dizer que as estratégias de F\&A alteraram as plataformas de produtos nas respectivas empresas e a análise indicou que a estratégia de $\mathrm{F} \& A$ se mostrou eficaz para as empresas 1 e 2, porém não para a empresa 3.

Para os entrevistados, o objetivo principal das empresas era o de se posicionar no mercado como fornecedor sistemista para as montadoras, disponibilizando sistemas completos de produtos após as F\&A. Certamente a adoção dessa estratégia afetou o desempenho comercial das empresas, com conseqüências financeiras não pesquisadas neste trabalho, pois o foco de interesse foi o de verificar se os novos produtos passaram a fazer parte das plataformas disponibilizadas às montadoras, em conseqüência da adoção das F\&A. 


\section{Conclusões Finais e Sugestões}

Silver (2000) afirma que o desafio da pesquisa exploratória é levantar teorias sobre as variáveis relacionadas aos negócios e depois coletar e analisar dados para verificar se nossa idéia se mantém no mundo real. Partindo da hipótese formulada no início deste estudo exploratório, com base no referencial teórico levantado e após a coleta, tratamento, análise e interpretação dos dados obtidos nas entrevistas em profundidade, pode-se então formular as considerações seguintes.

As indicações de que a estratégia de F\&A tenha sido eficaz para as empresas que a adotaram levou a uma tendência de manter a hipótese no mundo real, porém para sustentar sua comprovação torna-se necessária uma pesquisa mais abrangente no futuro, podendo partir das ferramentas de análise desenvolvidas neste trabalho. Além disso, esta primeira indicação não pode ser generalizada para toda a população em vista da limitação da amostra de três unidades organizacionais, orientada para este estudo exploratório.

Um aspecto fundamental neste trabalho foi o detalhe inserido no conceito de plataforma de produtos conforme Deschamps e Nayak (1997). Os autores afirmam que essa designação refere-se ao conjunto de todas as diferentes linhas e itens de produto que uma empresa possui e coloca à venda no mercado. $\mathrm{O}$ detalhe refere-se à afirmação “...e coloca à venda no mercado”. A partir dessa afirmativa, para se caracterizar um novo produto como pertencente a uma plataforma o mesmo deve, evidentemente, fazer parte dos produtos que a empresa efetivamente vende. Ao se verificar os resultados obtidos após as F\&A, verificouse que os novos produtos das Empresas 1 e 2 foram ofertadas ao mercado, podendo ser considerados pertencentes às suas respectivas plataformas, o que não ocorreu com o novo produto da Empresa 3. Dessa forma, baseando-se na afirmação acima de Deschamps e Nayak (1997, p. 150) e no conceito de eficácia de Gonçalves (1984), a estratégia de F\&A adotada pela Empresa 3 foi considerada não eficaz, pois não atingiu seu objetivo, ao não conseguir disponibilizar os novos produtos ao mercado.

Ao se verificar o tempo gasto em cada F\&A, percebeu-se que este durou dois, cinco e quatro anos nas empresas 1,2 e 3, respectivamente. Confrontando o sucesso da empresa 1 com o fracasso da empresa 3, pode-se evidenciar algumas diferenças entre as empresas em exame. Na F\&A da empresa 1, a adquirida possuía um nível tecnológico e organizacional à altura das exigências das montadoras, além da vantagem de localizar-se dentro da Grande São Paulo, próxima do ambiente das montadoras, ao passo que a unidade adquirida da empresa 
3 situava-se na Argentina, afetada pela distância e pelas variações cambiais. Esses fatos sugeriram que os aspectos de compatibilidade e de vantagem estratégica entre a empresa 1 e sua adquirida eram, provavelmente, melhores que os da empresa 3 em relação à sua adquirida.

Conforme o referencial teórico, a freqüência de modificações na extensão das linhas é um possível indicador de tentativas não criativas de empresas no desenvolvimento e colocação de um produto no mercado. As expectativas antes da F\&A mostraram que as alterações pretendidas na plataforma de produtos não incorreram nessa falha, pois as novas linhas de produtos foram planejadas sob a influência das montadoras em cenário relativamente claro das necessidades que deveriam ser satisfeitas. As montadoras desejavam contar com fornecedores globais, implicando que as empresas de autopeças deveriam optar por uma estratégia eficaz na obtenção desse resultado.

Satomi (2000) ressalta que, devido ao follow sourcing, as empresas de autopeças passaram a se posicionar na mesma região geográfica das montadoras. Esse fato foi confirmado pelos entrevistados, ao revelarem que uma empresa de autopeças capaz de oferecer um sistema completo para a montadora deve ser capaz de atuar da mesma forma em qualquer continente. Por outro lado, os centros de desenvolvimento de novos produtos estão localizados nas matrizes das multinacionais, o que pode inibir o desenvolvimento de novos produtos nos países emergentes. Propõe-se verificar em um futuro estudo as conseqüências desse cenário na redução da capacidade de inovação e sua influência no crescimento tecnológico brasileiro.

Conforme o referencial teórico, a estratégia de F\&A é composta tipicamente por três etapas: pré-aquisição, diligência e negociações e pós-aquisição. Baseandose nas afirmações acima, se a estratégia no seu conjunto foi eficaz para as empresas 1 e 2, não eficaz para a empresa 3, e esse resultado foi conseqüência do gerenciamento dessas três etapas, surge outra questão interessante e que pode ser motivo de estudo junto a especialistas em F\&A: quais são os aspectos críticos a serem observados em cada uma dessas etapas, de modo a garantir a eficácia dessa estratégia na ampliação das plataformas de produtos nas empresas de autopeças.

Outro estudo a ser desenvolvido seria verificar o impacto das mudanças nas plataformas em relação ao desempenho econômico-financeiro das empresas, por meio de um pesquisa de caráter quantitativo.

Artigo recebido em 07.11.2003. Aprovado em 16.08.2004. 


\section{ReferênCIAs Bibliográficas}

ANSOFF, H. I.;

MCDONNELL, E. J.

Implantando a administração estratégica. 2. ed. São Paulo: Atlas, 1993. p. 590.

BALLOU, R. H.

Logística empresarial. 1. ed. São Paulo: Atlas, 1993. p. 387.

\section{BARDIN, L.}

Análise de conteúdo. 2. ed. Lisboa: Edições 70, 1979. p. 226.

\section{BARNEY, J. B.}

Looking inside for competitive advantage. The Academy of Management Executive, nov. 1995. Disponível em: <http:// proquest.umi.com/ pqdweb $>$. Acesso em: 4 july 2000.

\section{CHRISTOPHER, $\mathrm{M}$.}

A Logística do Marketing. 2. ed. São Paulo: Futura, 1999. p. 220.

CLEMENTE, N. M.; GREENSPAN, S.D.

Winning at mergers and acquisitions. 1. ed. USA: John Wiley \& Sons, Inc., 1998. p. 331.

DESCHAMPS, J. P.;

NAYAK, P. R.

Produtos Irresistíveis. 1. ed. São Paulo: Makron Books, 1997. p. 447.
GIL,A.C.

Métodos e técnicas de pesquisa social. 1. ed. São Paulo: Atlas, 1987. p. 206.

GONÇALVES, J. E. L.;

FISCHMANN, A. A.

Contribuição ao Entendimento da Utilização dos Conceitos de Eficácia e Eficiência em Administração de Empresas. 1984. 120 f. Dissertação (Mestrado em Administração) Faculdade de Economia e Administração, Universidade de São Paulo, São Paulo.

GORLE, P.;

LONG J.

Fundamentos de planejamento do produto. 1. ed. São Paulo: McGraw-Hill do Brasil, 1976. p. 120.

GROPPELLI, A.A.;

NIKBAKHT, E.

Administração Financeira. 2. ed. São Paulo: Saraiva, 1999. p. 535.

KERLINGER, F. N.

Metodologia da Pesquisa em Ciências Sociais: um tratamento conceitual. 1. ed. São Paulo: EPU, 1980. p. 378.

KEY, S. L.

Guia da Ernst \& Young para administração de Fusões e Aquisições. 1. ed. Rio de Janeiro: Record, 1992. p. 180. 
KOTLER, P.

Administração de marketing: análise, planejamento, implementação e controle. 5. ed. São Paulo: Atlas, 1998. p. 725

Marketing para o século XXI. 1. ed. São Paulo: Futura, 1999. p. 305.

MARCONI, M.A.de;

LAKATOS, E. M.

Técnicas de Pesquisa. 2. ed. São Paulo: Atlas, 1990. p. 260.

MARCOVITCH, J.;

ZACCARELLI, S. B.

Contribuição ao Estudo da Eficácia Organizacional. 1972. 113 f. Tese (Doutorado em Administração) Faculdade de Economia e Administração, Universidade de São Paulo, São Paulo.

MINTZBERG, H.; LAMPEL, J.

Reflecting on the Strategy Process. Sloan Management Review, USA, v. 40, n. 3, p. 21-30, Spring 1999.

PORTER, M. E.

Estratégia Competitiva. 18. ed. Rio de Janeiro: Campus, 1986. p. 362.

Como as Forças Competitivas Moldam a Estratégia. In: MONTGOMERY, C. A.; PORTER, M. E. Estratégia: a busca da vantagem competitiva. 4. ed. Rio de Janeiro: Campus, 1998.
PRAHALAD, C. K.;

HAMEL, G.

A Competência Essencial da Corporação. In: MONTGOMERY, C. A.; PORTER, M. E. Estratégia: a busca da vantagem competitiva. 4. ed. Rio de Janeiro: Campus, 1998.

RASMUSSEN, U. W.

Aquisições; Fusões \& Incorporações Empresariais. 1. ed. São Paulo: Aduaneiras, 1989. p. 168.

REED, S. F.;

LAJOUX, A. R.

The Art of M\&A - A Merger Acquisition Buyout Guide. 3. ed. New York: Irwin, 1995. p. 1011.

ROBLES, L. T.

A Prestação de Serviços de Logística Integrada na Indústria Automobilística no Brasil: em busca de alianças logísticas estratégicas. 2001. 176 f. Tese (Doutorado em Administração) Faculdade de Economia e Administração, Universidade de São Paulo, São Paulo.

ROCHA, F.;

IOOTY, M.;

FERRAZ, J. C.

Fusões e aquisições e rentabilidade na indústria brasileira na década de 90 . Instituto de Economia. Rio de Janeiro: Universidade Federal do Rio de Janeiro, 2000. p. 32. Estudo interno da UFRJ.

ROCK, M. L.;

ROCK, R. H.;

SIKORA, $\mathrm{M}$.

The mergers \& acquisitions handbook. 2 th ed. New York: McGrawHill, 1994. p. 551. 
SATOMI, L.

Montadoras põem US\$ 9,4 bi no Mercosul. Gazeta Mercantil Latino Americana, São Paulo, v. 5, n. 239, p. 1, 28-3027, nov. 2000.

SILVER, $M$.

Estatística para Administração. 4. ed. São Paulo: Atlas, 2000. p. 458.

\section{SINDIPEÇAS.}

Sindicato Nacional da Indústria de Componentes para Veículos Automotores, São Paulo. Brasil. Informativo. mar. 2002. Disponível em: <http:// www.sindipeças.org.br/noticias/ informativo.asp $>$. Acesso em: $1^{\circ}$ maio 2002.

STEINER, G. A.

Top Management Planning. 1. ed. New York: Macmillan Publishing Co., Inc., 1969. p. 795.

STONER, J.A. F.;

FREEMAN, E.

Administração. 1. ed. Rio de Janeiro: Livros Técnicos e Científicos, 1994. p. 533.
VERGARA, S C.

Projetos e Relatórios de Pesquisa em Administração. 2. ed. São Paulo: Atlas, 1998. p. 90.

WHEELWRIGHT, S. C.;

CLARK, K. B.

Creating Project Plans to Focus Product Development. Harvard Business Review, Boston, v. 7, n. 2, p. 70-82, mar./ apr. 1992.

WRIGHT, P.;

KROLL, M. J.;

PARNELL, J.

Administração Estratégica. 1. ed. São Paulo: Atlas, 2000. p. 433.

ZILBER, M.A.;

FISCHMANN, A. A.; PIEKNY,E.E.

Strategies of Growth: the alternative of mergers and acquisitions. In: BALAS, The Business Association of Latin American Studies, 2002, Tampa, Florida, USA. Anais..... Tampa, Florida, USA: Theoretical Models in Strategic Management, 2002. p. 1-16. 